\title{
Modernización del sistema registral peruano y venezolano: balance y perspectivas
}

\section{Elena María Vivar Morales Carlos Velandia Sánchez}

Primera parte : el sistema registral peruano

\section{Antecedentes}

El tema registral no fue de gran importancia en nuestro país hace algunas décadas atrás. Lo que se sabía de la institución de los registros públicos era que se trataba de algo sumamente complejo, al que tenían que acudir diariamente miles de personas quienes previamente debían cumplir con una serie de requisitos que las normas legales exigían, y tenían que perder tiempo e incurrir en onerosos gastos en las oficinas registrales para lograr inscribir sus títulos referidos a actos y contratos inscribibles, tanto en el Registro de Propiedad, como en los otros registros que en ese entonces se encontraban dispersos en diferentes entidades estatales.

El Registro de la Propiedad se creó en el Perú mediante la Ley del 2 de enero de 1,888, una ley que tenía 19 artículos a través de los cuales se normaba el proceso de inscripción y se implantaba en el Perú los Oficios de Hipotecas que provenían de España, que se crearon, dicho sea de paso, para contrarrestar la clandestinidad de las hipotecas ocultas en el Derecho antiguo a través de la publicidad registral.

Los registros aparecen en la historia de la humanidad en el momento en que el comercio se intensificó y, según cuentan los expertos, fueron los banqueros los que apoyaron la implementación de la institución para no ser burlados por sus acreedores con hipotecas ocultas.

En el caso de nuestro país su funcionamiento e implementación eran tan precarios que luego de más de cien años de su creación, se- 
guían funcionando con la misma técnica registral de inscripción y los mismos elementos que se crearon para una realidad en la que eran pocas las propiedades urbanas y rurales que se iban incorporando al registro y casi nulo el tráfico inmobiliario.

\section{Técnica registral tradicional}

\subsection{Inscripciones en tomos}

En los orígenes de la institución registral las inscripciones se hacían en tomos, grandes libros que tenían de 500 a 600 fojas y de ellas, cada seis o siete páginas conformaban lo que era la Partida Registral, es decir, aquella que en virtud del principio de especialidad debía corresponder en forma exclusiva y excluyente a un solo inmueble, el cual correspondía a un propietario determinado.

Después de utilizadas las cinco o seis páginas de una partida registral, las mismas que eran numeradas con números romanos, en las páginas siguientes se iban abriendo nuevas partidas registrales hasta terminar de utilizar las 600 fojas del tomo.

Esto implicaba que si las cinco o seis páginas que tenía asignada una partida registral en ese tomo se terminaban (por haberse hecho varios asientos registrales), se tenía que continuar la historia de un predio en otro tomo que tuviese fojas por utilizar. En consecuencia, el estudio de los antecedentes registrales de un predio se tenía que hacer en varios tomos, que en algunos casos sumaban de 15 a 20 tomos, lo cual dificultaba mucho el trabajo registral.

Dichos tomos en los que aparecían los asientos registrales de los actos y contratos que constituyen, modifican, transmiten, limitan o extinguen los derechos reales sobre inmuebles, no respondían a una orden establecido en forma técnica sino que estaban enumerados en números del 1 al 2,020.

Las propiedades así dispersas en los diferentes tomos correspondían a diferentes propietarios, sin considerar ningún tipo de clasificación, ni siquiera por distritos, para poder llevar las estadísticas de predios registrados que en algún momento alguna repartición del Estado podía necesitar. 
En los tomos, todos los asientos registrales se hacían en forma manual. Incluso, los números y cifras que se tenían que consignar en los asientos se hacían con letras y el trabajo lento se complicaba más aún en el caso de cometerse un error puesto que, según el mandato del Reglamento de Inscripciones, aprobado por Acuerdo de Sala Plena de la Corte Suprema de Justicia de 1968, se tenía que suspender y realizar uno nuevo, también en forma manual lo cual implicaba alargar más el tiempo de las inscripciones.

La culminación de todo este proceso demoraba, y como los tomos eran usados en forma indistinta por los usuarios propietarios de bienes inscritos en el mismo tomo, el trabajo se retardaba más ya que se tenía que esperar que un tomo sea desocupado por un registrador para poder practicar la inscripción de otro propietario cuyo predio estaba en el mismo tomo.

En forma paralela a la diaria demanda de tomos, éstos también eran requeridos por los registradores de gravámenes, quienes necesitaban dichos tomos para expedir las certificaciones de Copias Literales y Gravámenes que cientos de usuarios solicitaban al Registro.

Asimismo, al ser numerosos los tomos y ser requeridos diariamente en los diferentes pisos de las oficinas registrales, se necesitaba una infraestructura y gran cantidad de personas para trasladarlos a cada oficina, según los requerimientos.

De otro lado, los tomos ocupaban mucho lugar en la bóveda del registro, siendo dificultoso su almacenamiento.

En este contexto, la ex-ONARP (Oficina de Nacional de los Registros Públicos) contó con más de mil empleados en la oficina registral de Lima, que se encargaban de realizar todo el proceso de inscripción y garantizar la publicidad registral.

\subsection{Utilización de las fichas registrales}

El 18 de agosto de 1970 se aprobó la Ampliación del Reglamento de las Inscripciones, que establecía que el folio real se podía llevar en tomos o en fichas movibles. Se empezaron a utilizar, entonces, las fichas registrales, cartulinas que conformaban las nuevas partidas registrales y en las que los asientos registrales eran hechos a máquina de escribir, técnica de inscripción mecánica que hacía lento el proceso de inscripción ya que las fichas, antes de usarse, debían pasar por un 
proceso de microfilm que alargaba el proceso de inscripción y que contribuía a congestionar más el sistema.

Como se puede apreciar, la técnica de inscripción y de archivo de títulos inscritos se iba desbordando cada vez más por la demanda diaria de los usuarios y las necesidades de una economía de mercado, que se sustentaba en la agilidad que se debía dar en la realización de las transacciones comerciales.

Este sistema mecánico no ofrecía mayor garantía de seguridad jurídica dentro del proceso, ya que tanto las inscripciones en tomos o en fichas podían adulterarse o desaparecer con la correspondiente sanción a los infractores en la vía administrativa y posterior sanción en la vía penal -si fuera el caso-, pero con el grave perjuicio para los usuarios del Registro.

Estas técnicas de inscripción en tomos y en fichas en forma paralela se emplearon hasta el año 1995, año en que se dio una disposición interna del Registro en el sentido de que se dejaran de usar los tomos y sólo se usen las fichas registrales.

\section{El inicio de la modernización}

Pero, además de la demanda que provenía del sector formal, el Registro debió soportar gran asedio originado por los títulos de propiedad de los AA. HH.

La informalidad de la vivienda en el Perú fue un fenómeno que en sus inicios el Estado trató de ignorar, y luego reprimir; sin embargo, la realidad desbordó la falta de respuesta del Estado con una verdadera alternativa de vivienda para los pobladores de los AA. HH. que se convertían en el sector más importante y numeroso de la población en Lima.

La gran cantidad de títulos de propiedad que fueron entregados por los alcaldes en épocas electorales y que no cumplían con los requisitos legales mínimos, como tener previamente inscrito el plano perimétrico y el plano de lotización de los $\mathrm{AA}$. $\mathrm{HH}$. de los cuales formaba parte el propietario del título, era grande.

Al mismo tiempo, existían miles y miles de títulos de propiedad que estando bien emitidos es decir debidamente saneados tampoco podían registrarse por la deficiencia técnica registral. 
El sistema tradicional trató de responder a la demanda, implementando dos secciones de propiedad dentro del Registro de la Propiedad, destinadas a inscribir exclusivamente los títulos de propiedad y planos perimétricos y de lotización de los AA. HH.

Sin embargo, el sistema no caminó, el sistema mecánico fue desbordado por el ingreso masivo de títulos al Registro provenientes del municipio o de los pobladores que la labor manual, ya no podía realizar al ritmo de las necesidades.

En este contexto, aparece en la década del 80 una institución llamada Instituto Libertad y Democracia (ILD), dedicada a la investigación de la situación de la propiedad de los informales en el Perú y de las técnicas de titulación y registro de predios, entre otras actividades.

Después de más de 10 años de investigación, el ILD logró encontrar que el desarrollo económico de un AA. HH. dependía de la legalidad de su titulación. Esta propuesta novedosa y revolucionaria, formulada por su presidente, Hernando de Soto, está expresada con meridiana claridad en los párrafos siguientes:

«[...] de esta forma, en el momento que queda claro que el Estado no erradicará el asentamiento, los invasores comienzan a edificar con material noble. Estas edificaciones se convierten a su vez en un nuevo y poderoso sustento para el derecho espectaticio, por cuanto en el Perú es políticamente inaceptable demoler viviendas de material noble, a tal punto que puede considerárseles el primer título de propiedad sobre el terreno. El resultado de este proceso es un nivel de inversión en las viviendas que está en función del grado de seguridad legal que el Estado le confiera a los asentamientos. Así, a mayor seguridad, mayor inversión y a menor seguridad menor inversión [...] $)^{1}$

«[...] de esta manera, el ILD encontró que el valor de una vivienda en un asentamiento con seguridad legal era equivalente a 41 veces el de una vivienda en el otro asentamiento humano. Aún incluyendo el valor del terreno y no sólo el de la construc-

1 Hernando de Soto. El Otro Sendero: La revolución informal. Editorial El Barranco S.A., 1987 p. 24 Séptima Edición (Perú) 10,000 ejemplares 
ción, la vivienda en el asentamiento con seguridad legal tiene un equivalente a 12 veces el de aquella que no la tiene. Posteriormente y utilizando una muestra mayor de 37 asentamientos humanos, que cubrían todo el espectro de posibilidades y áreas de Lima, los investigadores del ILD determinaron que el valor promedio de las edificaciones con títulos de propiedad equivale a 9 veces el aquellas que no los tienen [...]” ${ }^{2}$

«[...] la importancia de los derechos de propiedad para el desarrollo ha sido subrayada por diferentes historiadores económicos que estiman que el auge de las innovaciones en occidente, y las grandes inversiones que las hicieron posible, comenzaron solamente a partir de finales del siglo XVIII, cuando los derechos de propiedad fueron perfeccionados $[\ldots]{ }^{3}$

En consecuencia, la única forma de lograr que el sector informal se incorpore al formal era a través del registro de su propiedad, ya que la consecuencia inmediata de esto era el acceso al crédito vía la inscripción de la hipoteca de su propiedad en el Registro.

El gran reto en la década de los 80 fue, para el ILD, lograr la modernización del sistema de inscripción registral de la propiedad inmueble en el Perú, cambiando el sistema mecánico por uno informatizado, facilitando así el ingreso masivo de información al registro y brindando seguridad total dentro del proceso de inscripción, de manera tal que no permitiera la pérdida de información registral y que rápidamente y a bajo costo realice las inscripciones de los pobladores de los $\mathrm{AA}$. HH. que, según sus tipos podían albergar $10,000,20,000$ o 30,000 potenciales títulos de propiedad.

Es así como en el año 1988, por primera vez en la historia de los registros en el Perú, el ILD sugiere la creación del Sistema de Registro Predial de Pueblos Jóvenes y Urbanizaciones Populares -hoy llamado Registro Predial Urbano-, lo que se hizo a través de los decretos legislativos 495 y 496 del 14 de noviembre de 1998. Posteriormente, a través del Decreto Legislativo No 667 se implementó la utilización de

2 Hernando de Soto. Op. cit. p. 25

3 Hernando de Soto. Op. cit. p. 225. 
este mismo sistema de inscripción de predios urbanos para los predios rurales en nuestro país.

El Registro Predial es un moderno sistema computarizado de inscripción de predios del sector informal, el mismo que el ILD lo patentó en el INDECOPI. En la expansión de este sistema hacia otros países, ha venido cambiando sus siglas y, así por ejemplo, tenemos a REGISSAL en el caso de la República de El Salvador, donde se implementó este sistema de inscripción y se logró registrar 140,000 predios en el primer año de su funcionamiento.

El Registro Predial marca un hito importante en el tema de modernización del Sistema Registral Nacional. En cuanto al Registro de la Propiedad Inmueble, tenemos que el único antecedente de registro computarizado en nuestro país era el Registro de Minería, pero que no incorporaba la nueva tecnología que traía el Registro Predial.

La modernización en el país no sólo se dio gracias a más de una década de investigación en el estudio de la situación de la propiedad en el sector informal y su exclusión del registro que realizó el Instituto Libertad y Democracia, sino que también tuvo su correlato en el ámbito legislativo.

El ILD encontró que más del $50 \%$ de predios en Lima eran de pobladores de AA. HH. y casi en su totalidad no estaban registrados. En Lima, sólo el 30\% de predios urbanos estaban registrados y $8 \%$ de predios rurales a nivel nacional, es decir, la mayor parte de la propiedad en el Perú estaba fuera del registro.

En el primer año de su funcionamiento, el Registro Predial logró inscribir una gran cantidad de títulos de propiedad, pero es realmente en el año 1993, luego de celebrase un convenio con el Banco Mundial, el ILD y el Registro Predial, cuando se llegó a inscribir más de 100,000 predios, cifra que constituyó un récord mundial.

Sin embargo, pese a tener el país un moderno sistema de inscripción, el problema del acceso al Registro continuaba. Las investigaciones del ILD fueron más allá y, como resultado de la ejecución del referido Convenio con el Banco Mundial, pudo determinar que miles de títulos de propiedad no se podían registrar, ya no sólo por la falta de un buen sistema de registro sino porque los títulos de propiedad no estaban sometidos a un verdadero procedimiento de saneamiento legal de la propiedad. 
Como respuesta a esta realidad, el ILD creó el PROFORM, el proceso de formalización de la propiedad informal, el mismo que también patenta en el INDECOPI y que en la actualidad se viene implementando en otros países como El Salvador, Haití, México y Egipto.

En cuanto al ámbito nacional se refiere, este sistema de saneamiento legal de predios viene siendo implementado por la COFOPRI (Comisión Nacional de Formalización de la Propiedad Informal) y es uno de los principales proyectos en materia de propiedad en el Perú. La idea central es «hacer del Perú un país de propietarios», slogan con el cual el ILD impulsó el trabajo del Registro Predial en 1993.

\section{Un logro en Latinoamérica}

Esta sala de datos técnicos que hacen referencia al proceso de modernización del sistema de inscripción registral en nuestro país, tiene como corolario un tema de calibre muy grande que ha merecido un reconocimiento intelectual en el exterior.

Recientemente la Revista Time una de las más importantes en Estados Unidos, acaba de premiar a Hernando de Soto como reconocimiento a la importancia de su pensamiento, conjuntamente con cuatro personajes importantes, por la grandeza de sus ideas, reconociéndolos como los líderes del nuevo milenio. Entre ellos figura Paulo Freire (educador brasileño), Bernardo Alberto Houssay (psicólogo argentino), Alberto Santos Dumont (aviador brasileño) y Luis F. Leloir (bioquímico argentino) todos ellos ya fallecidos.

La grandeza del pensamiento de Hernando de Soto radica en que ninguna economía de los países del tercer mundo desarrollaría si no se sustenta en la "formalización de los derechos de propiedad", esto implica el acceso al Registro y al consecuente crédito hipotecario de la banca formal.

Atribuye la pobreza en que viven miles de miles de personas a las leyes que no recogen la realidad, sino que tratan de imponer parámetros que son ajenos al derecho consuetudinario y que no son consignados en las normas. La burocracia estatal era tan fuerte que el más débil jamás podía cumplirla y, a causa de ello, permanece en su pobreza y es causa del consiguiente atraso económico de su país. 
Dice Hernando de Soto, «remuevan los obstáculos legales y los pobres se ayudarán a sí mismos». Esta es una de las revoluciones más grandes del pensamiento en Latinoamérica en materia de formalización de los derechos de propiedad.

La Ley de Simplificación Administrativa No 25035 es una de las leyes más importantes que se dio en Perú y nació en el ILD y, conjuntamente con los decretos legislativos 495 y 496 que crean el Registro Predial, han transformado la estructura administrativa del Estado peruano, ya que son cientos de leyes que después de la promulgación de esta Ley recogen en sus considerandos sus principios y se sustentan en ella. La modernización así iniciada en el tema registral ha continuado.

\section{Continuación de la modernización}

Después de haberse creado en 1988 un Registro de Propiedad totalmente computarizado utilizado, en principio, para la inscripción de los predios del sector informal, en el año 1994 se dio la Ley No 26366 que creó el Sistema Nacional de los Registros y la Superintendencia Nacional de los Registros Públicos, como un organismo autónomo del Sector Justicia y ente rector del Sistema Nacional de los Registros Públicos del país.

La Ley dispondría la integración, bajo la competencia de SUNARP, de todos los registros jurídicos existentes en los diversos sectores públicos.

Una de las principales actividades del ente recién creado fue implementar la modernización del sistema de inscripción que se aplicaba en la Oficina Registral de Lima y Callao, ORLC, y en las oficinas registrales Regionales a lo largo de todo el país.

La técnica de inscripción en tomos a que hicimos referencia al inicio del artículo, fue utilizada en dichas oficinas hasta el año 1970, fecha en que la Junta de Vigilancia revisó esta técnica que consideró inadecuada dado la demora del trabajo, el gran espacio que ocupaban los tomos, y el costo que implicaba pagar al personal que tenía que trasladar los tomos desde la bóveda hasta las oficinas registrales para el trabajo diario.

En este contexto, el 18 de agosto de 1970 la ampliación del Reglamento de las Inscripciones, en su Art. $2^{\circ}$, dispuso que el folio real debía llevarse en fichas movibles. 
Sin embargo, la técnica del uso de fichas tampoco brindaba seguridad jurídica ni aseguraba la intangibilidad de los asientos registrales que debían brindar los registros.

Las fichas podían desaparecer $y$, al ser un sistema de numeración manual, se prestaba a errores de los técnicos que al numerarlas manualmente podían repetir el número, generándose a su vez dos partidas registrales con un mismo número, lo cual anulaba el principio de especialidad registral en virtud del cual a cada inmueble le corresponde una única partida registral en forma exclusiva y excluyente.

De otro lado, el movimiento económico era cada vez mayor y las fichas, de un tamaño reducido y con casilleros pequeños para el llenado de los asientos registrales, no eran apropiadas teniendo que continuarse la partida en otras fichas. Esto hacía que la situación patrimonial de una persona en la partida registral se encontrara dispersa en decenas de fichas que eran difíciles de obtener en forma inmediata.

Al ser los asientos hechos a máquina de escribir se produjo, en algunos casos, falsificaciones de asientos por alguno de los técnicos, incluyendo la firma y sello de los registradores, lo cual era una grave anomalía que el registro permitía al no poder detectar en forma inmediata el hecho y al estar amparados estos asientos por la publicidad registral, ocasionando grave perjuicio a los terceros.

La manifestación de tomos y fichas siempre se dio accediendo los usuarios en forma personal al estudio de ellos o pidiendo copias certificadas al Registro, proceso que demoraba por la complejidad en obtener los tomos y las fichas que eran requeridas por otros usuarios al mismo tiempo.

En consecuencia, existía en el país dos registros de propiedad de predios paralelos, uno moderno en el que sólo se registraban los títulos de propiedad del sector informal y otro para el sector formal. La necesidad de la modernización del sistema tradicional era inminente.

\section{Modernización del sistema de la SUNARP}

Tanto la informática como la tecnología de punta son en esta época de gran importancia para el desarrollo de cualquier institución.

La SUNARP, consciente de este gran reto, que con el transcurrir del tiempo viene desarrollando cada vez con mayor intensidad y gran 
dedicación, ha fijado como una de sus metas principales la total modernización del Sistema de Inscripción Registral.

Hoy en día existe en el sistema de registro de la SUNARP la partida electrónica registral. Las partidas se identifican a través de una codificación que se produce al momento que se ingresa un predio por primera vez al Registro, es decir cuando se efectúa la inmatriculación, desmembración, independización o acumulación de un predio en el Registro de Propiedad Inmueble o en cada uno de los otros registros, como el de Sociedades, cuando se constituye una persona jurídica, o en el Registro de Bienes Muebles, cuando se inmatricula un bien, produciéndose todas las inscripciones posteriores referente a la partida bajo un mismo número.

La partida electrónica se implementa en la SUNARP a partir de la expedición de la Resolución SUNARP 124-97 del 15 de agosto de 1 997, la que aprueba la sustitución del archivo registral existente en la Oficina Registral de Lima y Callao por un sistema de microarchivos y la implementación de una nueva técnica de inscripción basada en la generación de asientos electrónicos, que quedan almacenados en el sistema y que aseguran su inalterabilidad y su integridad.

El contenido de la partida registral ha sido previamente escaneado y luego grabada en los discos ópticos; además, este sistema se sustenta en un dispositivo de captura de huella digital conocido como firma electrónica.

La nueva técnica de inscripción se sustenta en la utilización de discos ópticos que son el soporte de las inscripciones.

Esta tecnología permite almacenar gran cantidad de información y se maneja a través de la computadora.

La implementación de esta nueva tecnología para efecto de la publicidad registral tiene su base legal en el artículo $234^{\circ}$ del C. P. C., que fue modificado por la Ley No 26612 en la que se consideraban documentos a las microformas tanto en la modalidad de microfilm como en la modalidad de soportes informáticos.

Este sistema no permite la alteración de los asientos registrales y brinda una seguridad total en el proceso de inscripción. Además, tiene una gran capacidad de almacenamiento de información utilizando un pequeńo espacio.

La huella dactilar es otra de las transformaciones trascendentales del nuevo sistema de inscripción, ya que los asientos registrales se 
constituyen en un medio idóneo y eficaz para identificar al registrador que autorizó la inscripción, siendo un signo distintivo que no admite prueba en contrario respecto a la identidad de éste, cuya huella quedó gravada en el sistema.

La modernización ha llegado a tal punto que recientemente la SUNARP ha hecho de conocimiento público, en la revista Panorama Registral, la implementación del SIR, el que tiene las siguientes características:

1) Consulta al sistema. Se logra a través de cualquier computadora que esté conectada al sistema. Ofrece la ventaja de poder consultar los expedientes registrales.

2) El acceso por índices. Permite acceder a la información e imágenes de la computadora a partir de búsquedas por razón social de los nombres, direcciones.

3) Almacenamiento. Que hace directamente en la base de datos.

4) Inviolabilidad. Las imágenes de las fichas registrales se graban directamente en discos compactos con la garantía de inviolabilidad del documento registral.

5) Seguridad. El sistema cuenta con mecanismos que permiten asegurar la integridad de la información registral. Entre ellos, la huella dactilar, que permite identificar inequívocamente al respectivo registrador, evitándose de esta manera cualquier intromisión en la calificación registral. ${ }^{4}$

\section{Un registro multiutilitario para el futuro}

Un registro moderno y computarizado tiene que contar necesariamente con una fidedigna base catastral, de tal manera que la correlación que debe haber entre el catastro y el registro sea perfecto y pueda brindar mucha utilidad al Estado y a los particulares.

$\mathrm{Al}$ respecto, tenemos que recientemente el Consejo de Bogotá, a través de su obra conmemorativa por sus 450 años de axistencia Es-

4 Revista Panorama Registral, Volumen II. Oficina Registral de Lima y Callao. 
quema de la Institución Catastral, nos presenta una serie de funciones que el catastro vinculado al Registro puede brindar cuando se encuentra implementado de manera adecuada.

Siguiendo tales lineamientos y vinculando su función a la labor registral, podemos afirmar que un registro moderno, con un sistema de inscripción registral computarizado, con incorporación de la base geográfica e interconectado vía módem a otros sistemas computarizados del Estado puede brindar los siguientes beneficios:

\subsection{Empresas públicas}

\subsubsection{Servicios básicos}

1) Realización de obras públicas.

2) Instalación de agua.

3) Instalación de redes telefónicas.

4) Instalación de empresas de acueductos y alcantarillado.

5) Diseños de redes eléctricas.

6) Políticas de servicios urbanos por equipamientos.

\subsubsection{Ordenamiento urbanístico}

7) Facilita la elaboración de un plan vial y clasificación de vías.

8) Facilita la definición de alternativas de solución al comercio ambulatorio, transporte, seguridad vial, recreación y esparcimiento.

9) Permite desarrollar las políticas urbanísticas de acondicionamiento territorial y usos del suelo.

10) Permite determinar los centros de deportes (áreas verdes).

11) Eficacia en la administración de los bienes inmuebles del Estado.

12) Políticas de planificación y gestión urbana.

13) Deslinde municipal, perímetro urbano y nomenclatura general.

14) Apoyar a los planificadores y políticos cono un instrumento útil y adecuado para tomar decisiones en política urbana y agropecuaria, arrendamiento, propiedad horizontal, etc.

15) Disponibilidad de elementos de planeación y control, en especial del desarrollo urbano.

16) Consulta y procesamiento de información en forma descentralizada por parte de entidades distritales y de organizaciones comunitarias. 
17) Información operativa y confiable sobre disponibilidad de predios para urbanizaciones populares, para el mejoramiento de inquilinatos y para definir la política del gobierno distrital en materia de tierras y vivienda.

18) Facilita el control urbano, sectorización y zonificación.

19) Inventario del patrimonio histórico y su recuperación.

20) Ecología urbana.

21) Banco de datos indispensable y de necesario uso para las dependencias y organismos estatales.

22) Incremento de la eficacia administrativa por ahorro en los recursos humanos, costos y tiempos en los trámites de las entidades estatales.

23) Permite desarrollar políticas de apoyo a la generación de empleo y al desarrollo socio-económico.

\subsubsection{Formación de base geográfica}

24) Los mapas son necesarios en todas las etapas de un censo o encuesta, en la planificación, en la recopilación de datos y en la presentación y análisis de los resultados.

25) Datos gráficos, a través del cómputo oportuno y útil.

26) Identificación de cada uno de los predios.

27) Ubicación y numeración del predio dentro de la carta catastral nacional.

28) Plano y croquis del predio con indicación de sus colindantes.

29) Elaboración de documentos gráficos, estadísticas y listas de propietarios o poseedores.

30) Implementar un sistema computarizado que permite la creación de una base de datos cartográficos y catastral única para todos los procesos cartográficas que regulen las entidades.

31) Disminuir los tiempos en los trámites que requieren insumos cartográficos.

32) Creación de una base cartográfica, única e integral.

33) Organizar el uso adecuado de los suelos.

34) Generación de información básica sobre infraestructura y el estado físico.

\subsubsection{Aspecto Fiscal}

35) Determinación de las zonas homogéneas físicas y estudio del 
mercado inmobiliario para determinar el valor de los terrenos y edificaciones.

36) Liquidación del autoavalúo catastral en cada predio.

37) Al fijar la base del cobro del impuesto predial (avalúo catastral) el catastro coopera en la fijación de este tributo que, al igual que los demás impuestos, debe ser justo.

38) Facilita la captación del impuesto a las rentas, del impuesto de alcabala y predial; identifica evasores.

\subsubsection{Planificación estatal}

39) Titularidad de propietarios e inquilinos.

40) En agricultura sirve para implementar la consolidación parcelaria.

41) Facilita la administración de terrenos agrícolas.

42) Estudio de suelos para determinar la calidad, lo cual constituye un mecanismo valioso para una mejor asignación de los recursos en el sector agropecuario y como ayuda en la Reforma Agraria, base de la política sectorial.

43) Brinda adecuada información territorial.

44) Facilita información para la operación de entidades de seguridad, defensa civil, bomberos, policía, etc.

45) Facilita la participación de arquitectos y abogados como verificadores en el ordenamiento urbanístico y agrícola.

\subsection{Empresas privadas}

46) Facilita la realización de contratos de asistencia técnica o de asesoría.

47) Sistematización, métodos procesamientos contables y presupuestales.

48) La programación, trámites administrativos y fiscales, formulación de cuentas y demás actividades que tiendan a racionalizar el trabajo y aumentar la eficiencia de la prestación de los servicios.

49) Integración de diferentes tipos de información, obtenidos de diversas fuentes, evitando duplicidad en los inventarios de los recursos y logrando economía en tiempos y servicios.

50) Brinda información para la ejecución y seguimiento de obras públicas.

51) Confiable información sobre terrenos y edificaciones.

52) Facilita el corretaje inmobiliario. 
53) Agiliza negocios sustentados en la propiedad.

54) Permite el acceso inmediato a los actos y contratos registrados.

55) Información literal y gráfica en forma instantanea.

\subsection{Ciudadanos}

56) Sirve para determinar la situación patrimonial inmobiliaria de un individuo en un momento determinado.

57) Sirve para oponer frente a terceros los derechos registrados.

58) Para facilitar el tráfico jurídico inmobiliario.

59) Para legitimar al titular del derecho inscrito.

60) Ampara los derechos de propiedad y posesión de los inmuebles y los derechos reales constituidos sobre ellos.

61) Facilita el crédito inmobiliario

62) Comprueba la existencia material del inmueble con sus singularidades.

En el caso peruano, aparte de la modernización del sistema de inscripción registral, se viene poniendo en práctica el uso de la cartografía computarizada, habiéndose dado declaraciones por funcionarios del Estado que en los departamentos de Arequipa y San Martín, donde se ha realizado la titulación basada en la cartografia computarizada, las tierras han aumentado su capacidad de hipoteca en un 1,000 por ciento.

Como se puede apreciar, el Perú se encuentra en pleno proceso de modernización del sistema de titulación y registro de predios, proceso que lo ubica entre los países latinoamericanos de mayor desarrollo en el tema.

Somos consecuentes que el reto es grande pero con todos los procesos de cambio que se vienen implementando, pronto estaremos a la par de muchos países desarrollados.

\section{Reflexiones}

- Después de más de cien años de existencia del Registro en el Perú; se ha determinado con claridad la importancia del Registro de la Propiedad, para el país, y la necesidad de modernización del Siste- 
ma Registral que facilita la incorporación de los propietarios informales al Registro para acceder a los beneficios del crédito hipotecario

- Si bien es cierto que el uso de la informática en un sistema de registro agiliza el sistema de inscripción, lo vuelve simplificado, rápido y seguro, no sirve de sustento para una plena eficacia registral necesaria en una economía de mercado, en la que la rapidez de las transacciones son indispensables, si previo a este cambio no hay una adecuada normatividad que permita el saneamiento físico legal de los predios materia de registro, y permita la incorporación de un capital muerto a la transacción propia de la economía moderna.

- Todo proceso de modernización está sustentado en el elemento humano, elemento central del proceso. En consecuencia, la idea es seguir profundizando el nivel de capacitación intelectual, formación humana y ética de los funcionarios del Registro, lo que conduce a una calidad total en la mejora del sistema registral de cualquier país.

- La creación de un registro de bienes muebles es un complemento indispensable de nuestro actual sistema de registro, ya que en la actualidad no existe como tal, sino que solamente agrupa al Registro de Propiedad Vehicular y a todos los registros de prendas que estaban dispersos en otras entidades estatales antes de crearse la SUNARP.s

Segunda parte : el sistema registral venezolano

\section{Antecedentes}

El Sistema Registral venezolano, al igual que en la mayoría de países de América Latina, tienen su origen en la Real Pragmática del 31 de enero de 1768, redactada por Campomanes y Florida Blanca, que

5 NOTA: El artículo contiene parte de las ponencias de la autora tanto, en el XII Encuentro del Comité Latinoamericano de Consulta Registral (llevado a cabo en la ciudad de Lima en el año 1997) como en el XIV Encuentro del Comité Latinoamericano de Consulta Registral (realizado en la República de Venezuela por la ASORESVEN - Asociación de Registradores Venezolanos). 
instituyó en España los Oficios o Contadurías de Hipoteca, instituidos en la Gran Colombia con el nombre de Oficios o Anotaciones de Hipoteca, con el objeto de conocer las situaciones jurídicas de las fincas y los gravámenes hipotecarios sobre las mismas, y de esta manera proteger a los eventuales adquirientes de los bienes hipotecados, de la ocultación y operaciones clandestinas que eran comunes en la época.

A partir de la fecha, los instrumentos públicos autorizados por los escribanos o notarios tenían que presentarse al Oficio o Anotador de Hipotecas, sin cuyo requisito no se producían efectos en juicio o fuera de él. De esta manera, surgieron dos clases de índices: uno de Titulares, y el otro, de Fincas, señalada por el nombre de los propietarios y el Código de las Fincas, con todo lo cual, se estaban iniciando los "elementos propios de un Registro Inmobiliario» en atención al trabajo realizado por el notario concatenado con el registrador.

Sin embargo, el Oficio de Anotación o Contaduría de Hipotecas, que constituía un verdadero intento de organización viene a sufrir una verdadera crisis que produce una completa desfiguración del Sistema Notarial Registral, ya que nuestra primera Ley de Registro Público, la del 22 de mayo de 1826, de la Gran Colombia, fue dictada con propósitos netamente financieros. «Necesitados de aumentar las Rentas Nacionales (expresa la Exposición de Motivos), se incorpora a la Hacienda Pública el Oficio de Anotación de Hipotecas, que, en adelante tendrá carácter de Registro para anotar o registrar los actos civiles, judiciales o extrajudiciales, a fin de sujetarlos de un impuesto". En consecuencia, la nueva ley, lejos de servir para cumplir una exigencia histórica como lo era darle publicidad a los negocios jurídicos y en especial sobre las cargas y gravámenes, se convertía en un instrumento de recaudación de recursos fiscales dependiendo directamente de la Hacienda Pública.

Posteriormente, la Ley del 24 de mayo de 1836, que constituye históricamente el origen del actual Registro Público, se crean las oficinas principales y subalternas y se ordena transcribir en los protocolos los actos mas variados, a saber: «Nacimientos, Muertes y Matrimonios, la publicación de Leyes, los Contratos, Fianzas, Testamentos, Poderes, Protestas, declaraciones, o cuales fuera otros actos extrajudiciales o privados igualmente», los títulos o despachos de empleados, las patentes de navegación y los privilegios exclusivos (artículos $9^{\circ}$ y $1^{\circ}$ ). Por otra parte, se suprime la institución de los escriba- 
nos o notarios, lo que se tradujo en una decisión totalmente negativa, ya que el Registro se convierte en un Sistema Mixto al suprimirse las notarías y con ello las funciones notariales; se produce entonces una inevitable confusión, ya que las funciones notariales pasaron a los registradores y secretarios de tribunales, produciéndose de esta manera, un híbrido y una mixtura, que desnaturaliza, a partir de 1836, la función y esencia de un verdadero registro, en el cual se inscriben además de las operaciones sobre inmuebles, otras como, testamentos, poderes, capitulaciones matrimoniales, sociedades civiles, etc.

Esta situación se mantuvo aproximadamente hasta el año 1952, en que se concentraron las funciones notariales exclusivamente de las notarias públicas, y en aquellos lugares donde no existían notarias, dicha función se encomendó a los juzgados de municipios y pasaron a ser de la competencia del Registro Subalterno y se ha mantenido en las leyes subsiguientes el sistema de inscripción en tomos y por duplicado debiendo enviarse un ejemplar del mismo, una vez finalizado el trimestre en la oficina principal de registro competente.

En principio, cada tomo contenía 200 folios útiles, destinados a inserción manuscrita de documentos, con sus respectivas notas de apertura y cierre, firmadas por el juez civil competente y el registrador subalterno. A partir del año 1980, por Decreto Presidencial del mes de julio de 1979, se avanzó un tanto en el mecanismo, sustituyéndose el sistema manuscrito e imponiéndose en todo el país la inscripción bajo el método de fotocopiado; es decir, los documentos presentados para su inscripción son fotocopiados por duplicado y con dichas fotocopias se van formando tomos que deben contener un máximo de cincuenta (50) documentos.

Por otra parte, el legislador venezolano incorporó dos mecanismos para controlar el tráfico inmobiliario; uno es la "Nota Marginal", consagrada en el Código Civil del año 1873, pero fue en el año 1925 cuando se incorporó como exigencia en la Ley de Registro Público; y el otro mecanismo fue la incorporación del principio del "Tracto Sucesivo".

De esta manera ha venido funcionando la institución registral en Venezuela, caracterizada fundamentalmente por encontrarse dentro del marco normativo de la colonia y continuidad republicana, quedando conceptualmente al margen de la clandestinidad. 
En Venezuela hemos tenido veinte leyes de registro público, las cuales han aportado pocos avances, salvo la vigente Ley de Registro Público de 1993, señalada anteriormente, la cual incorporó las siguientes innovaciones:

a) Creó el manejo de la Administración de los Registros Públicos, a través de la figura de los Servicios Autónomos sin Personalidad Jurídica, figura ésta que ha contribuido al mejoramiento y a la modernización de la mayoría de nuestras oficinas de registros públicos sin que signifique al Estado una carga presupuestaria.

b) Incorporó la elaboración de una «ficha registral», conteniendo toda la información referente a los inmuebles ubicados en cada jurisdicción registral, a fin de asentar en ella todas y cada una de las operaciones o medidas que recayeran sobre los inmuebles. En esta ficha registral se deben inscribir la operación inmobiliaria tomando en cuenta el inmueble con sus características propias, código catastral, linderos, superficie, ubicación exacta, así como la imposición de gravámenes y limitaciones sobre el mismo y sus extinciones, así como la transmisión de la propiedad, lo que sin duda alguna contribuirá a la creación de un sistema donde el inmueble sea el objeto principal de la operación y los propietarios, acreedores hipotecarios, etc., son elementos circunstanciales que pueden variar en el tiempo.

Este avance significativo en nuestro sistema registral se ha visto trabado un tanto por la falta de un programa de control catastral, con el cual se obtendría una identificación exacta de cada uno de los inmuebles. No obstante, se ha venido implementando la ficha registral por fases, bajo sistema automatizado.

Igualmente, este articulado reciente en la Ley de Registro Público, nos permite usar microfilms, medios magnéticos y electrónicos para la formación del tomo duplicado lo cual también representa un verdadero avance del sistema.

c) Estableció la posibilidad de incorporar en la actividad registral, el uso de los avances informáticos, lo cual sirvió de fundamento para que el Gobierno Nacional dictara un Decreto en el año 1998, mediante el cual autorizaba la sustitución del tomo duplicado por sistemas digitalizados. 
d) Como se reitera, eliminó definitivamente las funciones notariales que venían ejerciendo los tribunales de municipio, en aquellas jurisdicciones que carecían de notarias públicas.

\section{Organización del sistema registral venezolano}

La institución registral en Venezuela nace de la obligación que tiene el Estado de tomar el control de la actividad registral al tráfico inmobiliario, para así garantizar a los venezolanos la seguridad jurídica de sus operaciones, y preservar uno de los más importantes y sagrados principios democráticos establecido en nuestra Constitución Nacional, como lo es el derecho de propiedad.

Por otra parte, el Código Civil Venezolano, consagra la institución del Registro Público; y la Ley de Registro Público, como ley especial, regula la organización del Sistema Registral Venezolano. En efecto, dicha ley, prevé que las Oficinas de Registro Público se dividen a su vez, en oficinas principales y oficinas subalternas de registro.

Las oficinas principales de Registro Público, entre otras funciones, se encarga de mantener y conservar en sus archivos, un ejemplar de todas las actuaciones que se realizan en los demás registros públicos incluyendo los registros subalternos. Existe una Oficina Principal de Registro en la capital de la República y en cada una de las capitales de los estados.

En las oficinas subalternas de Registro Público es donde se ejerce el control de todas las operaciones que realizan los particulares con respecto a bienes inmuebles, a través de un funcionario investido por el Estado venezolano de dar Fe Pública, denominado Registrador Subalterno, quien al suscribir los instrumentos y emitir las certificaciones dota a los actos de efectos jurídicos contra terceros.

Las oficinas subalternas de registro se encuentran distribuidas en todo el ámbito del territorio nacional, funcionando una como mínimo, en la ciudad cabecera de los municipios de los estados. Dependiendo del desarrollo inmobiliario de las diferentes localidades, se ha ido incrementando el número de oficinas, llegando a existir en la actualidad más de doscientas en todo el territorio nacional. Es importante destacar que cada oficina subalterna de registro abarca y está sometida a la jurisdicción impuesta por la ley o decreto que las crea. 
Pero la actividad de los registros subalternos no se circunscribe a la rama inmobiliaria. Tanto el Código Civil venezolano como otras leyes de la República le atribuyen a los documentos que otorgan estas instituciones, Fe Pública y defectos erga omnes. Así tenemos el caso de las asociaciones, fundaciones y cualquiera otra sociedad de carácter civil, cuya responsabilidad o vida jurídica la adquieren a partir de la protocolización del Acta Constitutiva ante la oficina subalterna de registro correspondiente.

Igualmente, se registran en las citadas oficinas de registro, los documentos relativos a las regulaciones especiales que adopten los futuros contrayentes en matrimonio con relación a sus bienes, como lo son las capitulaciones matrimoniales, que solo son válidas si se protocoliza el documento contenido de las mismas, antes de la celebración del matrimonio.

Otros documentos, como son los de Tutela, Curatela, Separación de Cuerpos y de Bienes entre cónyuges y otros de carácter familiar, también están sometidos a las formalidades registrales.

Los documentos contentivos de Mandato, Poder, Nombramiento de Factor Mercantil y otros en los cuales, personas naturales o jurídicas delegan su presentación en un tercero, así como sus revocatorias, renuncias o sustituciones, también adquieren efectos ante terceros, al ser protocolizados en la oficina subalterna de registro. Las manifestaciones de última voluntad, tales como testamentos abiertos o cerrados, codicilos, legados, así como sus modificaciones y revocatorias, son en su totalidad, materia de registro subalterno.

Otras operaciones de carácter especial, sometidas a la formalidad registral, son las contempladas en la Ley de Hipoteca Mobiliaria y Prenda sin Desplazamiento de Posesión, que por su carácter especialísimo su control fue atribuido a los registros subalternos a los fines de dotar de seguridad jurídica plena a los acreedores de los créditos regulados por dicha ley.

\section{Técnica de inscripción registral}

Desde los comienzos de la actividad egistral en Venezuela, en la época colonial, así como después de la promulgación de la primera Ley de Registro Público en el año 1936, se impuso y se ha seguido mante- 
niendo en todas las leyes subsiguientes el sistema de inscripción en tomos, es decir, los actos que contienen las operaciones que son llevadas al Registro Subalterno, que es el Registro de bienes inmuebles, se inscriben en tomos. Esta inscripción se realiza por duplicado, debiendo enviarse un ejemplar del mismo, una vez finalizado cada trimestre a la Oficina Registral de Registro competente.

En principio, cada tomo contenía 200 folios útiles, destinados a inserción manuscrita de documentos, con sus respectivas notes de apertura y cierre, firmadas por el juez civil competente y el registrador subalterno. A partir del año 1980, por Decreto Presidencial del mes de julio de 1979, se avanzó un tanto en el mecanismo, imponiéndose en todo el país la inscripción bajo el método de fotocopiado; es decir, los documentos presentados para su inscripción son fotocopiados por duplicado y con dichas fotocopias se van formando tomos que deben contener un máximo de (50) documentos.

Este es el mecanismo que aún prevalece. Sin embargo, en las mas recientes leyes de Registro Público, desde el año 1993 en adelante, se trata de enfocar el sistema un poco más hacia la identificación propia del inmueble como tal, ya que se desarrolla un artículo referente a la inscripción mediante la creación de la «ficha egistral", donde se debe inscribir la operación inmobiliaria tomando en cuenta el inmueble con sus características propias, código catastral, linderos, superficie, ubicación exacta, así como la imposición de gravámenes y limitaciones sobre el mismo y sus extensiones, así como la transmisión de la propiedad, lo que nos hace deducir que vamos hacia la creación de un sistema donde el inmueble sea el sujeto principal de la operación y los propietarios, acreedores hipotecarios, etc., son elementos circunstanciales que pueden variar en el tiempo.

Este avance significativo en nuestro sistema registral se ha visto trabado un tanto por la falta de un programa de control catastral, con el cual se obtendría una identificación exacta de cada uno de los inmuebles. No obstante, se ha venido implementando la "ficha registral» por fases, bajo sistema automatizado.

Igualmente, este artículo reciente en la Ley de Registro Público nos permite usar microfilms, medios magnéticos y electrónicos para la formación del tomo duplicado, lo cual también representa un verdadero avance del sistema. 
Para efectos de la inscripción de documentos la propia Ley de Registro Público y la Ley de Hipoteca Mobiliaria y Prenda Sin Desplazamiento de Posesión, ordenar clasificar la inscripción de los documentos de acuerdo al acto que contienen, en los protocolos $1^{\circ}, 2^{\circ}, 3^{\circ}$, $4^{\circ}$, de Hipoteca Mobiliaria y Prenda Sin Desplazamiento de Posesión.

En el protocolo $1^{\circ}$, se insertan la mayoría de las operaciones inmobiliarias como compraventa, hipotecas, cancelaciones, cesión de créditos, sociedades civiles, participación de bienes; igualmente, según el reglamento de Hierros y Señales, se inscriben las operaciones sobre animales de cría .

En el protocolo $2^{\circ}$, se inscriben documentos que tienen que ver con el aspecto familia, tales como, Tutelas, Curatelas, Sentencias de Divorcio, Separación de Cuerpos, Capitulaciones Matrimoniales, etc.

En el Protocolo $3^{\circ}$, se inscriben documentos contentivos de Mandatos, todo tipo de Poderes, Sustituciones, Renuncias y Revocatorias. Asimismo, se inscriben en este protocolo operaciones con características mercantiles donde se involucran inmuebles, tales como Aportes a Capital.

En el Protocolo $4^{\circ}$, se inscriben documentos que contienen todo tipo de Manifestaciones de Última Voluntad, Testamentos Abiertos y Cerrados, Revocatorias de los mismos, Codicilos, etc.

En el Protocolo de Hipoteca Mobiliaria, según la Ley Especial sobre la materia, se inscriben documentos donde bienes muebles son datos en garantía. En el Protocolo de Prenda Sin Desplazamiento de Posesión se insertan documentos donde bienes muebles son objetos de Garantía Prendaria.

\section{El cambio en el sistema registral venezolano}

En las pasadas elecciones, Venezuela expresó su deseo de cambio, mensaje que tiene un alcance conceptual y genérico con el cual la Asociación de Registradores Subalternos de Venezuela, que me honro en presidir, no sólo está totalmente de acuerdo, sino que, desde hace aproximadamente dos años viene trabajando en la reestructuración, modernización y fortalecimiento de las actividades que realizan las oficinas subalternas de registro, concentrando esfuerzos para la crea- 
ción del Registro Inmobiliario, que hasta hoy no existe en nuestro país, porque seguimos operando con el Sistema de Inscripción mediante documentos tomos y protocolos (Folio Personal) mientras que el resto de los países del mundo mantienen la información de cada unidad inmobiliaria adoptando el sistema del Folio Real, constituyendo nuestra más clara ambición, aportarle al país ese sistema. Es de observar que nuestro procedimiento actual fue idóneo en el pasado, pero hoy resulta evidentemente obsoleto. Afortunadamente ese empeño viene produciendo frutos. En las múltiples reuniones de trabajo realizadas por los registradores subalternos, tanto en el país como en el exterior, nos ha permitido visualizar claras metas de esa transformación indispensable. En ese sentido, son muchos los Registros que vienen adelantando su automatización. Recientemente se procedió a elaborar el Manual de Normas y Procedimientos para las Oficinas Subalternas de Registro. Se autorizó la sustitución del tomo duplicado por medios electrónicos. Se instrumentó la elaboración de la "ficha registral" y se ha comprobado exitosamente, la interconexión con el Ministerio de Justicia. Todos estos objetivos se cristalizaron con el apoyo oportuno de este despacho ministerial.

ASORESVEN, hoy por hoy como asociación integrada por profesionales, con experiencia y técnicamente vinculados al desarrollo y perfeccionamiento del Sistema Registral Venezolano, aporta de manera permanente al usuario, al registrador, al ministro de Justicia y otras instituciones, ideas innovadoras y sugerencias oportunas. Igualmente, ha promovido cursos de mejoramiento profesional, planificación de talleres, congresos nacionales e internacionales que indudablemente constituyeron criterios modernos y factores de cambio en beneficio de la sociedad civil organizada, siendo éste nuestro principal compromiso.

Estamos conscientes de que ese proceso de cambio profundo debe hacerse sin alterarse la continuidad del servicio público prestado. El diseño de la nueva estructura debe hacerse en forma tal que los usuarios perciban la calidad del servicio a través de un Registro Inmobiliario moderno y transformado igual o mejor a los que existen en otros países.

Es obligatorio mencionar que el nuevo Registro no debe ser una organización aislada, sino parte de un sistema integral en el cual se encuentren incorporadas las áreas o competencias correspondiente al 
Registro Civil con todo el alcance requerido por las personas naturales y las jurídicas; el Registro Mercantil como funciona hoy en día, pero con algunos perfeccionamientos indispensables y la creación de un Registro para Vehículos Automotores, Naves, Aeronaves y Maquinaria Pesada. En el entendido que la integración significa también la interconexión permanente entre estos y las notarías, con el objeto de fortalecer la seguridad jurídica que el Sistema Registral debe garantizar a la colectividad. La propiedad privada es parte fundamental de la democracia y el sistema registral integral es el garante de ella.

El sistema antes descrito presenta una forma de descentralización institucional, proceso lógico y conveniente en razón del crecimiento cuantitativo y cualitativo de la nación. Va a formar parte integral de la sociedad civil con razón de ser propia, porque el funcionamiento de las comunidades así lo requiere. Ese sistema responde a lo que es normal en los países avanzados: transparencia, eficiencia y seguridad jurídica. Será parte del sector público el que tendrá a su cargo su rectoría y control, a través de una Superintendencia de Registros y Notarías, ente especializados para cumplir esas funciones en la modernización que se propone.

Dentro de los objetivos logrados, merece especial mención el convenio de cooperación técnica suscrito el 14 de julio de 1998 entre la República de Venezuela y el Banco Interamericano de Desarrollo, mediante el cual se logró el aporte no reembolsable de US\$150.000 con el objeto de formular un programa de modernización, automatización y fortalecimiento institucional del Sistema Registral Venezolano, labor que realiza actualmente el Ministerio de Justicia en coordinación con el BID. Dicho esfuerzo debe materializarse mediante un seguimiento adecuado.

El cambio iniciado es un proceso sistemático destinado a sustituir un sistema que tiene más de cincuenta años de atraso, por estructuras modernas que van a ser de las más avanzadas del mundo. Hoy contamos con un diagnóstico estructural claro y se estudian con detenimiento los detalles que le permitirán a Venezuela tener el Sistema Registral que el país necesita en este momento histórico. 


\section{Retos para el próximo milenio}

- Conversión del Folio Personal al Folio Real, en atención a las experiencias recibidas por ASORESVEN, en catorce jornadas nacionales y la presencia internacional en los siguientes eventos:

- Lima, 1997

- Panamá, 1998

- Cuba, 1998

- Marruecos, 1998

- Méjico, 1999

- XIV Encuentro Latinoamericano de Consulta Registral celebrado en Margarita, Venezuela.

- Reciente visita a Buenos Aires, Montevideo y Lima.

- Creación de la Escuela de Capacitación Registral como organismo de alta calificación técnica y operativa(carácter práctico).

- Avances de Informática (no copiar sino transformar de acuerdo a nuestra experiencia propia).

- Estandarización de los sistemas o programas de informática y futura interconexión con instituciones involucradas: SENIET, Registros, Notarías, Ministerio de Relaciones Interiores y de Justicia y otros.

- Profundización de los convenios de asistencia técnica celebrados durante el XIV Encuentro Latinoamericano de Consulta Registral, celebrado en Margarita, Estado Nueva Esparta, Venezuela, con asistencia de delegados de Perú, Argentina, Uruguay, España y Brasil. 